\title{
CULTIVO DE MILHO EM SISTEMA DE PLANTIO DIRETO EM PASTAGEM INOCULADA COM AZOSPIRILLUM BRASILENSE
}

\author{
Rubson da Costa Leite ${ }^{1 *}$, Guilherme Octávio de Sousa Soares ${ }^{1}$, Robson da Costa Leite ${ }^{2}$, José Geraldo \\ Donizetti dos Santos ${ }^{3}$, Tiago Barbalho André ${ }^{4}$, Antônio Clementino dos Santos ${ }^{3}$
}

\begin{abstract}
RESUMO - São diversos os estudos sobre inoculação em gramíneas com bactérias Azospirillum brasilense. Porém pouco se sabe sobre o efeito residual da inoculação. São necessários estudos que visem avaliar o efeito no solo pela inoculação dessas bactérias em associação com plantas. Mediante a importância da associação de gramíneas com bactérias com capacidade de fixar biologicamente o Nitrogênio, objetivou-se avaliar características agronômicas em plantas de milho (Zea mays L.) sobre plantio direto em pastagem inoculada com Azospirillum brasilense com doses de Nitrogênio. O delineamento experimental utilizado foi em blocos casualizados, em esquema fatorial $4 \times 2$, com quatros repetições, totalizando 32 unidades experimentais de $9,0 \mathrm{~m}^{2} \mathrm{cada}$. Os tratamentos foram constituídos por plantio direto em pastagem com e sem inoculação de Azospirillum brasilense (estirpes Abv 5 e Abv 6) e com doses de $\mathrm{N}$ em cobertura no capim $\left(0,12,5,25\right.$ e $\left.50 \mathrm{~kg} \mathrm{ha}^{-1}\right)$. Foram avaliados os parâmetros: altura de plantas, diâmetro de colmo, comprimento da espiga, diâmetro da espiga e peso da espiga. O plantio direto de milho sob pastagem inoculada com Azospirillum brasilense promove incremento nas características diâmetro e peso de espigas de milho. Diferentes doses de nitrogênio residual na pastagem não influenciam o milho em sucessão em sistema de plantio direto.
\end{abstract}

Palavras chave: adubação nitrogenada, bactérias diazotróficas, inoculante, Zea mays L.

\section{CULTIVATION OF CORN UNDER NO-TILLAGE SYSTEM IN PASTURE INOCULATED WITH AZOSPIRILLUM BRASILENSE}

\begin{abstract}
There are several studies on inoculation in grasses with Azospirillum brasilense bacteria. However, little is known about the residual effect of inoculation. Studies are needed to evaluate the effect on soil by inoculating these bacteria in association with plants. Due to the importance of the association of grasses with bacteria with the ability to biologically fix Nitrogen, the objective was to evaluate agronomic characteristics in maize (Zea mays L.) plants on no-till on pasture inoculated with Azospirillum brasilense with Nitrogen doses. The experimental design was a randomized complete block design, in a $4 \times 2$ factorial scheme, with four repetitions, totaling 32 experimental units of $9.0 \mathrm{~m}^{2}$ each. The treatments were constituted by no-till on pasture with and without inoculation of Azospirillum brasilense (Abv 5 and Abv 6 strains) and with $N$ doses in grass cover $\left(0,12,5,25\right.$ and $\left.50 \mathrm{~kg} \mathrm{ha}^{-1}\right)$. The following parameters were evaluated: plant height, stalk diameter, ear length, ear diameter and ear weight. Direct planting of maize under pasture inoculated with Azospirillum brasilense promotes an increase in the diameter and weight characteristics of corn cobs. Different doses of residual nitrogen in pasture do not influence corn in succession in no-tillage system.
\end{abstract}

Keywords:diazotrophic bacteria, inoculant, nitrogen fertilization, residual nitrogen.

\footnotetext{
${ }^{1}$ Pós-Graduando em Ciência Animal Tropical, Universidade Federal do Tocantins, Campus Araguaína; *Autor para correspondência: rubsonif@gmail.com

${ }^{2}$ Pós-Graduando em Produção Vegetal, Universidade Federal do Tocantins, Campus Gurupi.

${ }^{3}$ Docente do curso de Zootecnia da Universidade Federal do Tocantins, Campus Araguaína.

${ }^{4}$ Engenheiro Agrônomo da Universidade Federal do Tocantins, Campus Araguaína.
} 


\section{INTRODUÇÃO}

A cultura do milho se posiciona entre os cereais mais importantes para a alimentação humana e animal. De acordo com dados estimativos da Conab (2017), a produção brasileira de grãos de milho atingirá em torno de 91,47 milhões de toneladas, sendo 29,86 milhões na primeira safra e 61,61 milhões de toneladas na segunda safra. Valores estes que representam $40 \%$ da produção de grãos esperada. Demonstra-se a importância dessa cultura para a economia brasileira.

Entre os nutrientes com maior importância para alto potencial produtivo para esta cultura, destacase o Nitrogênio, que tem contribuído significativamente para os bons resultados do cultivo desse grão. No entanto, apesar de ser o elemento mais abundante na atmosfera terrestre, os solos, em sua maioria, apresentam baixo teor de $\mathrm{N}$ disponível, tornando a prática de adubação nitrogenada imprescindível (Cunha et al., 2014; Dartora et al., 2013). Essa prática representa um dos custos mais elevados do processo produtivo (Nunes et al., 2015; Sangoi et al., 2015). Ademais que, apenas $50 \%$ do $\mathrm{N}$ via fertilizante aplicado ao solo é aproveitado pelas plantas, onde o restante perdido por lixiviação, volatilização, e outros fatores (Repke et al., 2013).

Entre os efeitos negativos causados pelo uso de fertilizantes químicos nitrogenados, Brum et al. (2016) e Kaneko et al. (2016) citam o excesso de nitrato nos mananciais. Como alternativa para a redução de custos e minimização dos impactos ambientais causados pela inserção de fertilizantes nitrogenados ao solo tem-se a Fixação biológica de nitrogênio - FBN.

A FBN, realizada por microrganismos diazotróficos, trata-se do processo de transformação do $\mathrm{N}_{2}$ na forma inorgânica combinada $\mathrm{NH}_{3}$, através da enzima nitrogenase que atua na quebra da ligação tríplice do N, logo após a amônia é rapidamente convertida a amônio $\left(\mathrm{NH}^{+4}\right)$, que na forma de glutamina é assimilada pela célula vegetal (Novakowiski et al., 2011; Reis \& Teixeira, 2005; Sangoi et al., 2015). Uma das técnicas para a FBN em gramíneas é a associação com esses microrganismos diazotróficos, que são bactérias promotoras de crescimento em plantas - BPCP, possuindo a capacidade de colonizar a superfície das raízes, rizosfera, filosfera e tecidos internos das plantas (Hungria, 2011).
Dentre as bactérias estudadas para FBN em gramíneas, principalmente em milho, destaca-se as do gênero Azospirillum (Hungria, 2011; RodriguezSalazar et al., 2009). Esse gênero tem importância por ser promotor de crescimento em plantas, através da alteração hormonal nas mesmas, onde auxiliam na produção de hormônios como auxinas, citocinina, giberelinas e etileno, além de fixarem $\mathrm{N}_{2}$ para a planta (Sangoi et al., 2015).

Mediante a importância da associação de gramíneas com bactérias com capacidade de FBN, o presente exposto tem como objetivo avaliar características agronômicas em plantas de milho sobre plantio direto em pastagem inoculada com Azospirillum brasilense em doses de Nitrogênio.

\section{MATERIAL E MÉTODOS}

O experimento foi realizado na Universidade Federal do Tocantins - Campus Araguaína, Escola de Medicina Veterinária e Zootecnia (EMVZ). A região é classificada como ecótono Cerrado e Floresta Amazônica, com clima do tipo Aw (quente e úmido), de acordo com a Classificação Internacional de Köppen (Alvarez et al., 2013), precipitação anual média de $1.863 \mathrm{~mm}$, altitude média de $240 \mathrm{~m}$ e umidade do ar com média de $78 \%$. O solo da área experimental apresenta textura arenosa, sendo classificado como um Neossolo Quartzarênico Órtico típico (Tabela 1).

Foi utilizado o delineamento experimental em blocos casualizados, em esquema fatorial $4 \times 2$, com quatro repetições, totalizando 32 unidades experimentais de $9,0 \mathrm{~m}^{2}$ cada. Os tratamentos foram constituídos por plantio direto em pastagem com e sem inoculação de Azospirillum brasilense (estirpes Abv 5 e Abv 6) e doses de $\mathrm{N}$ em cobertura no capim $\left(0,12,5,25\right.$ e $\left.50 \mathrm{~kg} \mathrm{ha}^{-1}\right)$.

O plantio efetuado no dia 10 de abril de 2017 com a semeadura de 2 sementes por cova, onde posteriormente realizado o desbaste quando as plantas atingiram três folhas expandidas. Utilizou-se a tecnologia do híbrido PW2B512, que apresenta plantas precoces com aptidão para grão e silagem. No momento do plantio, uma adubação com $30 \mathrm{~kg} \mathrm{ha}^{-1}$ de $\mathrm{N}, 70 \mathrm{~kg} \mathrm{ha}^{-1} \mathrm{de}_{2} \mathrm{O}_{5}$, $60 \mathrm{~kg} \mathrm{ha}^{-1}$ de $_{2} \mathrm{O}$ e $100 \mathrm{~kg} \mathrm{ha}^{-1}$ de FTE (Fonte de micronutrientes). Durante alguns períodos prolongados de ausência de precipitação foi efetuada irrigação por aspersão, com finalidade de se atingir a capacidade 
Tabela 1 - Caracterização química do solo (camada 0-20 cm) da área experimental antes da implantação da pastagem. Araguaína-TO, 2017

\begin{tabular}{|c|c|c|c|c|c|c|c|c|c|c|c|c|c|c|}
\hline $\mathrm{Ca}^{2+}$ & $\mathrm{Mg}^{2+}$ & $\mathrm{Al}^{3+}$ & $\mathrm{H}+\mathrm{Al}$ & $\mathrm{SB}^{(2)}$ & $\mathrm{CTC}^{(3)}$ & K & $\mathrm{P}$ & M.O ${ }^{(1)}$ & $\mathrm{pH}$ & Areia & Silte & Argila & $\mathrm{V} \% \%^{(4)}$ & $\mathrm{m} \%$ \\
\hline & & - & $\mathrm{ol}_{\mathrm{c}} \mathrm{dm}^{-3}$ & & & & & $\mathrm{~g} \mathrm{dm}^{-3}$ & $\mathrm{CaCl}_{2}$ & & $(\%)$ & & & \\
\hline 1,46 & 0,63 & 3,0 & 9,9 & 3,25 & 13,9 & 2,0 & 3,1 & 14,2 & 4,5 & 89,35 & 0,65 & 10 & 29,2 & 42,3 \\
\hline
\end{tabular}

${ }^{(1)}$ M.O: Matéria Orgânica; ${ }^{(2)}$ SB: Soma de Bases; ${ }^{(3)}$ Capacidade de Troca Catiônica em pH 7,0; ${ }^{(4)}$ V\%: Saturação por Bases.

de campo do solo. As unidades experimentais constituídas por seis linhas de $3 \mathrm{~m}$ de comprimento, com espaçamento de $0,33 \mathrm{~m}$ entre plantas e $0,5 \mathrm{~m}$ entre linhas, totalizando stand de 60.000 plantas ha ${ }^{-1}$.

O controle de insetos e pragas realizados conforme a necessidade de acordo com o recomendado para a cultura, por aplicação e pulverização de defensivos químicos. A adubação de cobertura, na forma de ureia $(45 \%$ de $N)$ efetuada em dois momentos duas parcelas, quando as plantas apresentaram seis e oito folhas (estádios V6 e V8, respectivamente) completamente expandidas, sendo efetuada $50 \%$ da quantidade de $\mathrm{N}$ exigida pela cultura de acordo com Sousa \& Lobato (2004). Para a primeira adubação de cobertura adicionado fonte de Potássio (Cloreto de Potássio 60\% de $\mathrm{K}_{2} \mathrm{O}$ ) em complemento a adubação de plantio.

Aos trinta dias após emergência foram coletadas altura de plantas (AP30) e diâmetro de colmo (DC30) com a finalidade de se observar a influência das bactérias sobre o estádio inicial de desenvolvimento das plantas de milho. Quando as plantas atingiram ponto de colheita foram avaliados os seguintes parâmetros (seis plantas centrais de cada parcela): Altura da espiga (AE); Diâmetro da espiga (DE) e Peso de espiga (PE).

Os dados obtidos foram avaliados estatisticamente pela análise de variância, utilizando o teste $\mathrm{F}$ em nível de significância de 5\%. Quando os valores de F significativos, as médias dos fatores qualitativos (inoculação) foram comparadas entre si pelo teste de Tukey. Para avaliar o efeito das doses residuais da pastagem sobre o milho, foi aplicada uma análise de regressão polinomial, testando-se os modelos e posterior plotagem dos gráficos.

\section{RESULTADOS E DISCUSSÃO}

As análises de variância apresentaram resultados significativos para DE e para PE em função da inoculação com A. brasilense, já para os parâmetros CE, AP30 e DC30 não houve significância em função da inoculação (Tabela 2). Quanto a interação entre inoculação e doses de $\mathrm{N}$ residual, não teve diferença $(\mathrm{p}>0,05)$ para os parâmetros avaliados.

Para os parâmetros DE e PE a área que continha residual de forragem inoculada com $A$. brasilense apresentaram valores superiores quando comparados em plantio direto sob a forragem sem inoculação (Tabela 3). Como o DE foi superior em plantas de milho que cresceram em área com residual de pastagem inoculada, influenciou sobre o peso das espigas. Segundo Fanceli \& Dourado Neto (1999), o diâmetro da espiga influencia indiretamente o peso de grãos, assim um acréscimo no DE implica em maiores rendimentos em milho. Segundo Torres et al. (2014), o diâmetro da espiga está diretamente relacionado como o enchimento de grãos e com o número de fileiras de grãos por espiga.

Os resultados encontrados para DE e PE demonstram que mesmo após a inoculação efetuada durante o plantio da forrageira, as bactérias de Azospirillum brasilense permaneceram em quantidade suficiente para influenciar nos fatores de rendimentos do milho. Outra explicação para maior DE e PE nessas plantas, e dada por Sabundjian et al. (2013), estes mencionam, em seus trabalhos com inoculação de $A$. brasilense em plantas de milho, que a inoculação de espécies forrageiras pode incrementar a qualidade química da palhada para a cultura sucessora.

Os parâmetros CE, $\mathrm{AP} 30$ e DC30 não demonstraram influência da inoculação aplicada na forrageira. As espigas de milho apresentaram comprimento de espigas em média de 18, $58 \mathrm{~cm}$. Apesar de autores (Andrade et al., 2016; Brum et al., 2016) mencionarem a influência da inoculação com A. brasilense no crescimento e desenvolvimento das plantas de milho, devido a capacidade dessas em estimularem a produção de hormônios, o residual dessa inoculação não apresentou efeito sobre a altura e diâmetro das plantas de milho 30 dias após a germinação. 
Tabela 2 - Analise de variância para Comprimento de espiga (CE), Diâmetro da espiga (DE), Peso da espiga (PE), Altura de plantas aos 30 dias (AP30) e Diâmetro de colmo aos 30 dias (DC30) de plantas de milho em função de doses residuais de nitrogênio e inoculação com Azospirillum brasilense. AraguaínaTO, 2017

\begin{tabular}{|c|c|c|c|c|c|}
\hline Fonte de variação & $\mathrm{CE}(\mathrm{cm})$ & $\mathrm{DE}(\mathrm{cm})$ & $\mathrm{PE}(\mathrm{g})$ & AP30 (cm) & DC30 $(\mathrm{cm})$ \\
\hline Inoculação & $1,0995^{\mathrm{NS}}$ & $6,1734^{*}$ & $5,7555^{*}$ & $2,2880^{\mathrm{NS}}$ & $2,3973^{\mathrm{NS}}$ \\
\hline Doses & $1,3275-$ & $0,6745-$ & 0,4670 & 1,7544 & $0,7991-$ \\
\hline Blocos & $0,6029 \mathrm{NS}$ & $5,0086 * *$ & $5,5949 * *$ & $0,9160^{\mathrm{NS}}$ & $5,2740 * *$ \\
\hline Tratamentos & $0,8077^{\mathrm{NS}}$ & $1,6069 \mathrm{NS}$ & $1,0906^{\mathrm{NS}}$ & $2,3580^{\mathrm{NS}}$ & $0,8630^{\mathrm{NS}}$ \\
\hline Interação & $0,8425 \mathrm{Ns}$ & $1,0171^{\mathrm{NS}}$ & $0,1591^{\mathrm{NS}}$ & $2,9848^{\mathrm{NS}}$ & $0,4155^{\mathrm{NS}}$ \\
\hline $\mathrm{CV}(\%)$ & 6,53 & 5,58 & 12,97 & 5,31 & 6,32 \\
\hline
\end{tabular}

*, ** Significativos a 0,05 e $0,01 \%$ de probabilidade, respectivamente, segundo o teste $\mathrm{F}$. - Dados quantitativos, não se aplica o teste $\mathrm{F}$.

Tabela 3 - Comprimento de espiga (CE), Diâmetro da espiga (DE), Peso da espiga (PE), Altura de plantas aos 30 dias (AP30) e Diâmetro de colmo aos 30 dias (DC30) de plantas de milho sob plantio direto em forrageira com e sem inoculação com Azospirillum brasilense. Araguaína- TO, 2017

\begin{tabular}{cccccc}
\hline Inoculação com A. brasilense & $\mathrm{CE}(\mathrm{cm})$ & $\mathrm{DE}(\mathrm{cm})$ & $\mathrm{PE}(\mathrm{g})$ & $\mathrm{AP} 30(\mathrm{~cm})$ & $\mathrm{DC} 30(\mathrm{~cm})$ \\
\hline Com & $18,81250 \mathrm{~A}$ & $4,05000 \mathrm{~A}$ & $160,68130 \mathrm{~A}$ & $88,8750 \mathrm{~A}$ & $1,7750 \mathrm{~A}$ \\
Sem & $18,36250 \mathrm{~A}$ & $3,85625 \mathrm{~B}$ & $144,01880 \mathrm{~B}$ & $91,4375 \mathrm{~A}$ & $1,8375 \mathrm{~A}$ \\
\hline
\end{tabular}

Médias seguidas da mesma letra na coluna não diferem significativamente entre si pelo teste de Tukey $(\mathrm{P}<0,05)$.

Para as diferentes doses de $\mathrm{N}$ residual não houve ajuste a nenhum dos modelos de regressão, demonstrase que as doses aplicadas na forrageira não influenciaram as plantas de milho quando em plantio direto (Figura 1). A ausência de resposta em função das doses residuais de $\mathrm{N}$ pode ser explicada pela alta relação $\mathrm{C} / \mathrm{N}$ da forrageira utilizada (capim braquiária), onde o $\mathrm{N}$ aplicado que foi absorvido pelas plantas não estava disponível durante o experimento com as plantas de milho e o restante que não foi absorvido pela forrageira e perdido devido à alta mobilidade do $\mathrm{N}$.

Em trabalhos em que se avaliou o efeito da adubação nitrogenada residual sobre o milho, Carmeis Filho et al. (2016), não encontraram efeito das doses sobre as características do milho. Estes autores atribuem que o $\mathrm{N}$ aplicado durante o ciclo do milho minimizou o efeito do $\mathrm{N}$ residual sobre as plantas, também pela redução das perdas inorgânicas de $\mathrm{N}$ por processos naturais, minimizados pela prática de plantio direto.

Segundo Fernandes et al. (2008), a ausência de efeito residual é explicada pelo fato de que o fertilizante $\mathrm{N}$ inorgânico remanescente ocorre predominantemente na forma de compostos orgânicos. Dado este aspecto, o uso por culturas subsequentes permanece geralmente muito baixo.

Ao avaliar doses de $\mathrm{N}$ e de palha em sistema de plantio direto em milho, Lange et al. (2006), não encontraram aumento na produtividade de plantas de milho em função da palhada superficialmente aplicada. Estes autores mencionam que fatores como alta relação $\mathrm{C} / \mathrm{N}$ e alto teor de fibras impediram melhores resultados quando do fornecimento de palhada, também reiteram o fato desta palha ser adicionada superficialmente, o que pode ter ocasionado perdas de nutrientes mais voláteis, como é o caso do $\mathrm{N}$, e não são absorvidos pelas plantas de milho. Borghi et al. (2014), não encontraram influência do $\mathrm{N}$ residual na nutrição nitrogenada do milho em sucessão.

\section{CONCLUSÕES}

O plantio direto de milho sob pastagem inoculada com Azospirillum brasilense promove incremento nas características diâmetro e peso de espigas de milho.

Diferentes doses de nitrogênio residual na pastagem não influenciam o milho em sucessão em sistema de plantio direto. 

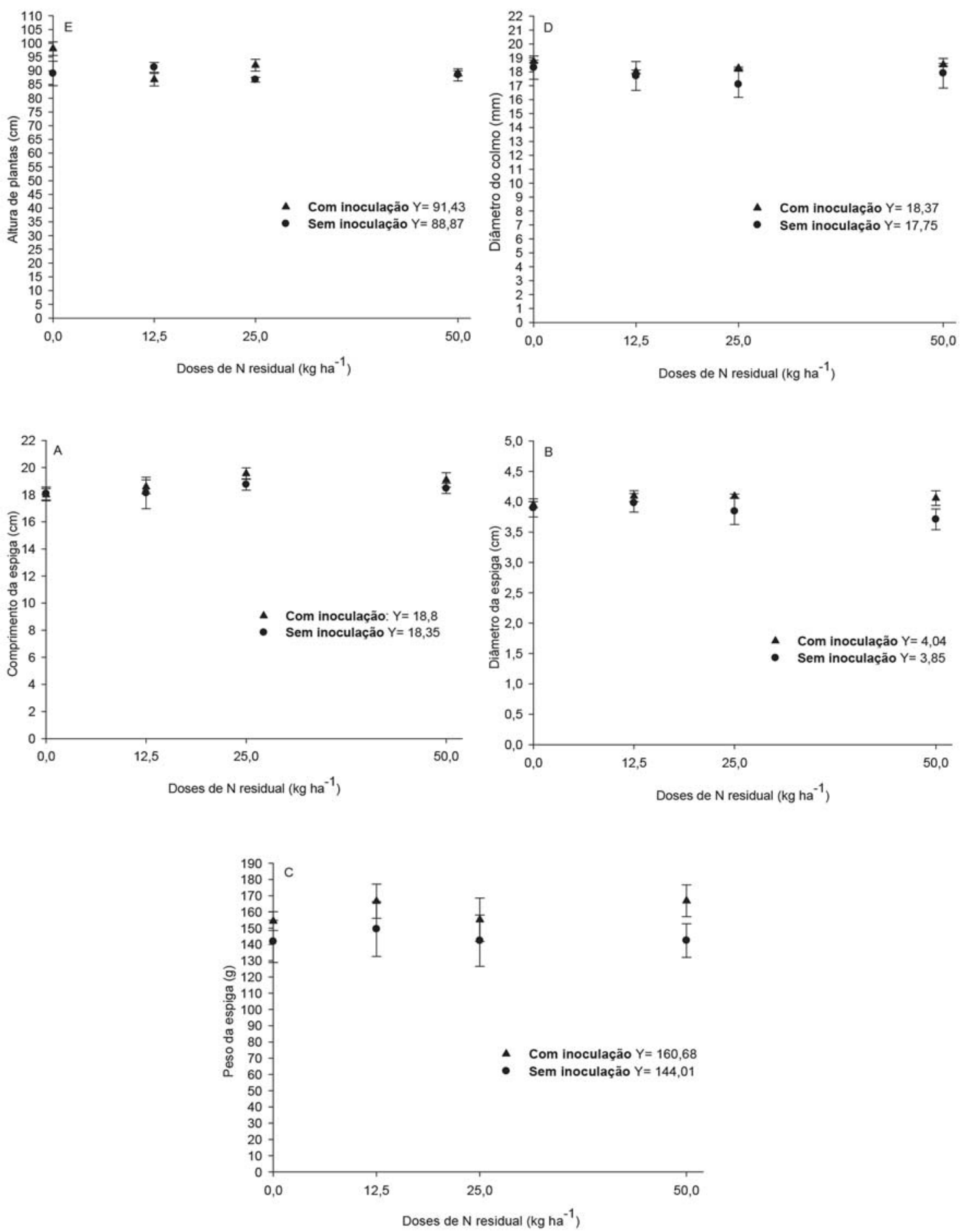

Figura 1 - Altura de plantas aos 30 dias de plantio, diâmetro de colmo aos 30 dias, comprimento de espiga, diâmetro de espiga e peso de espiga de plantas de milho sob residual de diferentes doses de nitrogênio. 


\section{LITERATURA CITADA}

ALVAREZ, C.A.; STAPE, J.L.; SENTELHAS, P.C. et al. Koppen's climate classification map for Brazil. Meteorologische Zeitschrift, v.22, n.6, p.711-728, 2013. DOI: 10.1127/0941-2948/2013/ 0507

ANDRADE, A.T.; CONDÉ, A.B.T.; COSTA, R.L. et al. produtividade de milho em função da redução do nitrogênio e da utilização de Azospirillum brasilense. Revista Brasileira de Milho e Sorgo, v.15, n.2, p.229-239, 2016.

BORGHI, E.; CRUSCIOL, C.A.C.; TRIVELIN, P.C.O. et al. Nitrogen fertilization (15NH4NO3) of palisade grass and residual effect on subsequent no-tillage corn. Revista Brasileira de Ciência do Solo, v. 38, p.1457-1468, 2014.

BRUM, M.S.; CUNHA, V.S.; STECCA, J.D.L. et al. Components of corn crop yield under inoculation with Azospirillum brasilense using integrated crop-livestock system. Acta Scientiarum. Agronomy, v.38, n.4, p.485-492, 2016.

CARMEIS FILHO, A.C.A.; CUNHA, T.P.L.; MINGOTTE, F.L.C. et al. Residual nitrogen fertilization effect of common bean production on succeeding corn intercropped with Congo grass.

Revista Ceres, v.63, n.4, p.576-583, 2016. DOI: 10.1590/0034-737X201663040019

CONAB - Companhia Nacional de Abastecimento. Acompanhamento da safra brasileira de grãos, v.4 - Safra 2016/17, n.7 - Sétimo levantamento, abril 2017.

CUNHA, F.N.; SILVA, N.F.; BASTOS, F.J.C. et al. Efeito do Azospirillum brasilense na produtividade de milho no sudoeste goiano. Revista Brasileira de Milho e Sorgo, v.13, n.3, p.261-272, 2014.

DARTORA, J.; GUIMARÃES, V.F.; MARINI, D. et al. Adubação nitrogenada associada à inoculação com Azospirillum brasilense e Herbaspirillum seropedicae na cultura do milho. Revista Brasileira de Engenharia Agrícola e Ambiental, v.17, n.10, p.1023-1029, 2013.
EMBRAPA (Empresa Brasileira de Pesquisa Agropecuária). Centro Nacional de Pesquisa de Solos. Sistema brasileiro de classificação de solos. 3.ed. Brasília: Embrapa, 2013.353p.

FERNANDES, F.C.S.; LIBARDI, P.L.; TRIVELIN, P.C.O. Parcelamento da adubação nitrogenada na cultura do milho e utilização do $\mathrm{N}$ residual pela sucessão aveia preta-milho. Ciência Rural, v.38, p.1138-1141, 2008.

FANCELLI, A.L.; DOURADO-NETO, D.

Tecnologia da produção de milho. Piracicaba: FEALQ/ ESALQ/USP, 1999. 360p.

HUNGRIA, M. Inoculação com Azospirillum brasilense: inovação em rendimento a baixo custo. Embrapa Soja, Londrina - PR, 2011.

KANEKO, F.H.; SABUNDJIAN, M.T.; ARF, O. et al. Análise econômica do milho em função da inoculação com Azospirillum, fontes e doses de N em cobertura. Revista Brasileira de Milho e Sorgo, v. 15, n.2, p.202-216, 2016.

LANGE, A.; CARVALHO, J.L.N.; DAMIN, V. et al. Doses de nitrogênio e de palha em sistema plantio direto de milho no cerrado. Revista Ceres, v.53(306), p.171-178, 2006.

NOVAKOWISKI, J.H.; SANDINI, I.E.; FALBO, M.K. et al. Residual effect of nitrogen fertilization and Azospirillum brasilense inoculation in the maize culture. Semina: Ciências Agrárias, v.32, suplemento 1, p.1687-1698, 2011.

NUNES, P.H.M.P.; AQUINO, L.A.; SANTOS, L.P.D. et al. Produtividade do trigo irrigado submetido à aplicação de nitrogênio e à inoculação com Azospirillum brasilense.

Revista Brasileira de Ciência do Solo, v.39, p.174-182, 2015.

REIS V.M.; TEIXEIRA K.R.S. Fixação biológica do nitrogênio - Estado da arte. In: AQUINO, A.M.; ASSIS, R.L. (Eds) Processos biológicos no sistema solo-planta: ferramentas para uma agricultura sustentável. Brasília: Embrapa Informação Tecnológica, v. 28, p.350-68, 2005. 
REPKE, R.A.; CRUZ, S.J.S.; SILVA, C.J. et al. Eficiência da Azospirillum brasilense combinada com doses de nitrogênio no desenvolvimento de plantas de milho. Revista Brasileira de Milho e Sorgo, v.12, n.3, p.214-226, 2013.

RIBEIRO, A.C.; GUIMARAES, P.T.G.; ALVAREZ, V.V.H. Recomendações para o uso de corretivos e fertilizantes em Minas Gerais - $\mathbf{5}^{\mathbf{a}}$ Aproximação. CFSEMG, Viçosa-MG, 1999. 159p.

SOUSA, D.M.G.; LOBATO, E. Cerrado: Correção do solo e adubação. Brasília: Embrapa Informação Tecnológica, 2004. 416p.

RODRIGUEZ-SALAZAR, J.; SUAREZ, R.; CABALLERO-MELLADO, J. et al. Trehalose accumulation in Azospirillum brasilense improves drought tolerance and biomass in maize plants. Federation of European Microbiological Societies, v.296, p.52-59, 2009.
SABUNDJIAN, M.T.; ARF, O.; KANEKO, F.H. et al. Adubação nitrogenada em feijoeiro em sucessão a cultivo solteiro e consorciado de milho e Urochloa ruziziensis. Pesquisa

Agropecuária Tropical, v.43, n.3, p.292-299, 2013.

SANGOI, L.; SILVA, L.M.M.; MOTA, M.R. et al. Desempenho agronômico do milho em razão do tratamento de sementes com Azospirillum sp. e da aplicação de doses de nitrogênio mineral.

Revista Brasileira de Ciência do Solo, v.39, p.1141-1150, 2015.

TORRES, F.E.; SOUZA, L.C.F.; ANDRADE, L.H.L. et al. Influência da cobertura do solo e doses de nitrogênio na cultura do milho safrinha. Revista Brasileira de Ciências Agrárias, v.9, n.1, p.36-41, 2014.

Recebido para publicação em 28/8/2017 e aprovado em 01/11/2017. 